\title{
IMPACT OF GENERIC AND MULTIBAND POWER SYSTEM STABLIZER (PSS) ON ELECTRIC POWER SYSTEM STABILITY
}

\author{
${ }^{1}$ Abolaji Stephen Korede, $\quad{ }^{2}$ Ulumefoh Usiholo Gabriel, ${ }^{3}$ Isichei Pius, ${ }^{4}$ Makinde Kayode. \\ ${ }^{1,2,3}$ Electrical/Electronic Department, Auchi Polytechnic, Auchi, Edo State, Nigeria. \\ ${ }^{4}$ Electrical Department, Federal Polytechnic, Bida, Niger State, Nigeria. \\ E-mail: stev4fire@gmail.com; dadajerome67@gmail.com; isicheiotoi1@gmail.com.
}

Kayodemakinde2004@yahoo.com

\begin{abstract}
Sustained power system oscillation has become a serious problem for power system operation and control nowadays. Oscillations cause safety problems in electric power equipment and limit the transmission capacity of long-distance power transmission. Oscillations can reach an amount that can compromise the stable operation of the synchronous generator and the power system in general. One way to suppress oscillations is to use a stabilizer of the power system as an integral part of the excitation systems of generators. The task of the power oscillation stabilizer is to produce a torque damping component of the electromagnetic torque through the excitation systems. This paper reveals the impacts of Generic and Multiband power system stabilizers (PSS) to enhance the damping of low frequency oscillations in a two machine power system. The impact of the Multiband PSS was seen to be better that of Generic PSS on the two machine power system in Matlab Simulink.
\end{abstract}

KEY WORD: Power, Stability, Simulation, Oscillations, Faults.

DOI: $10.7176 / \mathrm{CEIS} / 12-2-04$

Publication date: April $30^{\text {th }} 2021$

\section{INTRODUCTION}

Power systems are inherently nonlinear and undergo a wide range of transient conditions, which results in under damped low frequency speed as well as power oscillations that are difficult to control. Power system stability may be broadly defined as that property of a power system that enables it to remain in a state of operating equilibrium under normal operating condition and to regain an acceptable state of equilibrium after being subjected to a disturbance (Kunju, et al., 2016). Stability of power system needs to be maintained even when subjected to large low-probability disturbances so that the electricity can be supplied to consumers with high reliability. Power system dynamic performance is improved by the damping of system oscillations.

It is known that the power-system stabilizers PSS for generators and the supplementary controllers for flexible ac transmission system (FACT) devices are efficient tools for improving the stability of power systems through damping of low frequency modes (Cardenas, et al.,, 2013), where the frequency of these modes ranges from 0.2 to $2.5 \mathrm{~Hz}$. Power System Stabilizer (PSS) devices are responsible for providing a damping torque component to generators for reducing fluctuations in the system caused by small perturbations.

The Power System Stabilizer (PSS) is a control device which ensures maximum power transfer and thus the stability of the power system enhancement. The PSS has been widely used to damp electromechanical oscillations occur in power systems. If no adequate damping is available, the oscillations will increase leading to instability (Ali, 2013). 


\section{DAMPING POWER OSCILLATIONS}

A continually oscillatory system would be undesirable for both the supplier and the user of electric power. The definition of Stability describes a practical specification for an acceptable operating condition. This definition requires that the system oscillations be damped (Omar, Samir, Ahmed, 2016). Accordingly, a desirable feature in electric power systems, considered necessary for all intents and purposes, is that the system contain inherent features that tend to reduce (or eliminate) power oscillations.

\subsection{Power Oscillation Damping Strategies}

A number of strategies are available for damping low frequency oscillations in power systems. Of these, the Power System Stabilizer (PSS) is the most commonly used. It operates by generating an electric torque in phase with the rotor speed (Khaleghi et al.,, 2010). In most cases, the PSS works well in damping oscillations. However, because the parameters of PSS are tuned by the original system parameters, its control has less flexibility, which means the control results are far from ideal if the operating conditions and/or structures of the system change (Alok, Surya, 2013). Modern controllers used to damp power system oscillations include HighVoltage DC (HVDC) Lines, Static Var Compensators (SVCs), Thyristor-Controlled Series Capacitors (TCSCs), Thyristor Controlled Phase-Shifting Transformers (TCPSTs) and other such Flexible AC Transmission System (FACTS) equipment. FACTS devices provide fast control action and have the advantage of flexibility of being located at the most suitable places to achieve the best control results. As these controllers operate very fast, they enlarge the safe operating limits of a transmission system without risking stability (Abd-Elazim, Ali, 2012). FACTS devices are oft combined with Energy Storage Systems (ESS) to achieve higher efficiency and greater operational effectiveness. FACTS/ESS technology has the advantages in both energy storage ability and flexibility of its power electronics interface. FACTS/ESS also has capability to work as active and reactive power generation and absorption systems, voltage control systems, and to improve the transmission capability and system stability (Shahgholian, Haghjoo, 2011).

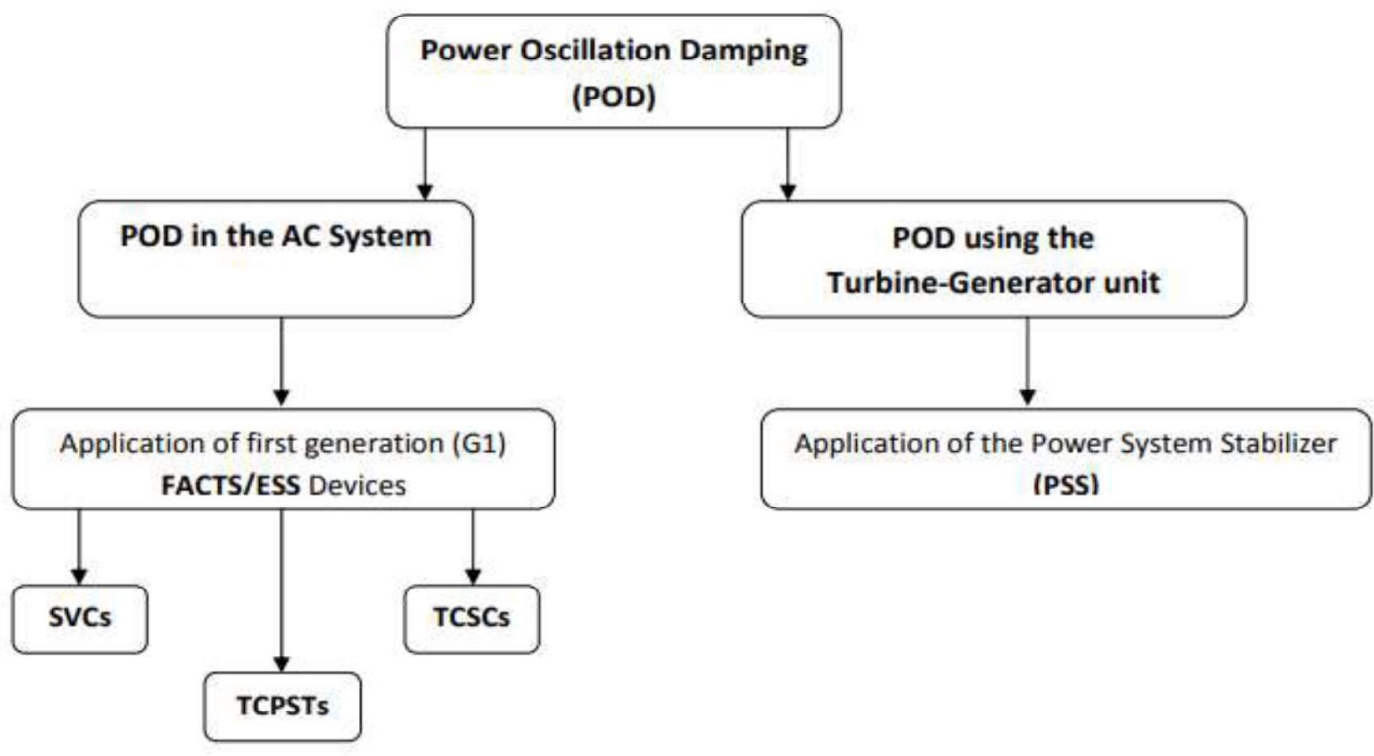

Fig.2.1: Power Oscillation Damping (POD) Strategies

\subsection{POWER SYSTEM STABILIZERS (PSSs)}

These are controllers with the ability to control synchronous machine stability through the excitation system by employing high-speed exciters and continuously acting voltage regulators. The PSS adds damping to the generator unit's characteristic electromechanical oscillations by modulating the generator excitation so as to develop components of electrical torque in phase with rotor speed deviations. The PSS thus contributes to the 
enhancement of small-signal stability of power systems. Fixed structure stabilizers generally provide acceptable dynamic performance. (Shahgholian, Shafaghi, et al.,, 2009).

2.3

OVERVIEW OF POWER SYSTEM STABILIZER (PSS) STRUCTURES

Shaft speed, electrical power and terminal frequency are among the commonly used input signals to the PSS. Different forms of PSS have been developed using these signals. This section describes the advantages and limitations of the different PSS structures.

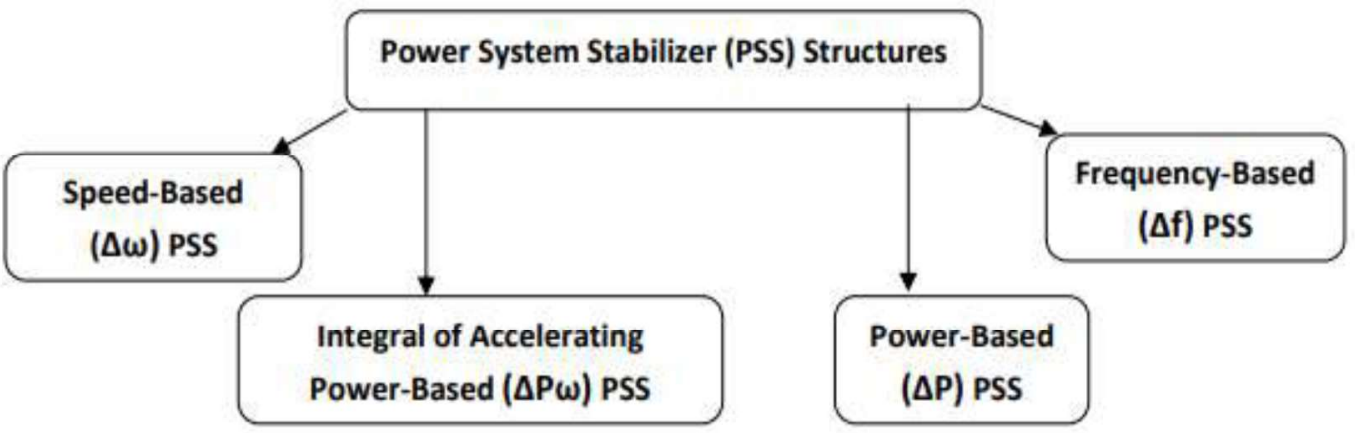

Fig 2.2: Overview of Power System Stabilizer (PSS) Structures

\subsubsection{SPEED-BASED $(\Delta \omega)$ STABILIZER}

These are stabilizers that employ a direct measurement of shaft speed. Run-out compensation must be inherent to the method of measuring the speed signal to minimize noise caused by shaft run-out (lateral movement) and other sources. While stabilizers based on direct measurement of shaft speed have been used on many thermal units, this type of stabilizer has several limitations. The primary disadvantage is the need to use a torsional filter to attenuate the torsional components of the stabilizing signal (Hossain, Hasan, 2014). This filter introduces a phase lag at lower frequencies which has a destabilizing effect on the "exciter mode", thus imposing a maximum limit on the allowable stabilizer gain. In many cases, this is too restrictive and limits the overall effectiveness of the stabilizer in damping system oscillations. In addition, the stabilizer has to be custom-designed for each type of generating unit depending on its torsional characteristics.

\subsubsection{FREQUENCY-BASED $(\Delta F)$ STABILIZER}

Here, the terminal frequency signal is either used directly or terminal voltage and current inputs are combined to generate a signal that approximates the machine's rotor speed, often referred to as compensated frequency. The frequency signal is more sensitive to modes of oscillation between large areas than to modes involving only individual units, including those between units within a power plant (Shahgholian, Eshtehardiha et al.,, 2008). Thus, greater damping contributions are obtained to these inter-area modes of oscillation than would be, with the speed input signal. Frequency signals measured at the terminals of thermal units contain torsional components. Hence, it is necessary to filter torsional modes when used with steam turbine units (Köse A., Irmak E. (2016). In this respect frequency-based stabilizers have the same limitations as the speed-based units. Phase shifts in the ac voltage, resulting from changes in power system configuration, produce large frequency transients that are then transferred to the generator's field voltage and output quantities. In addition, the frequency signal often contains power system noise caused by large industrial loads such as arc furnaces.

\subsubsection{POWER-BASED $(\triangle P)$ STABILIZER}

Due to the simplicity of measuring electrical power and its relationship to shaft speed, it was considered to be a natural candidate as an input signal to early stabilizers. The equation of motion for the rotor can be written as follows:

$$
\frac{\partial}{\partial t} \Delta \omega=\frac{1}{2 H}\left(\Delta P_{m}-\Delta P_{e}\right)
$$


Where:

$H=$ inertia constant; $\Delta P_{m}=$ change in mechanical power input; $\Delta P_{\varepsilon}=$ change in electric power output and $\Delta \omega=$ speed deviation.

If mechanical power variations are ignored, this equation implies that a signal proportional to shaft acceleration (i.e. one that leads speed changes by $90^{\circ}$ ) is available from a scaled measurement of electrical power. This principle was used as the basis for many early stabilizer designs (Khalid., Saleh, Ercelebi, 2015). In combination with both high-pass and low-pass filtering, the stabilizing signal derived in this manner could provide pure damping torque at exactly one electromechanical frequency. This design suffers from two major disadvantages. First, it cannot be set to provide a pure damping contribution at more than one frequency and therefore for units affected by both local and inter-area modes a compromise is required (Shahgholian, Faiz, 2010). The second limitation is that an unwanted stabilizer output is produced whenever mechanical power changes occur. This severely limits the gain and output limits that can be used with these units. Even modest loading and unloading rates produce large terminal voltage and reactive power variations unless stabilizer gain is severely limited. Many power-based stabilizers are still in operation although they are rapidly being replaced by units based on the integral-of- accelerating power design.

\subsubsection{INTEGRAL-OF-ACCELERATING POWER $(\triangle P \omega)$ STABILIZER}

The limitations inherent in the other stabilizer structures led to the development of stabilizers that measure the accelerating power of the generator. Due to the complexity of the design, and the need for customization at each location, a method of indirectly deriving the accelerating power was developed. The principle of this stabilizer is illustrated by rewriting equation (1) in terms of the integral of power.

$$
\Delta \omega=\frac{1}{2 H} \int\left(\Delta P_{m}-\Delta P_{e}\right) \partial t
$$

The integral of mechanical power is related to shaft speed and electrical power as follows:

$$
\int \Delta \boldsymbol{P}_{m} \partial t=2 H \Delta \omega+\int \Delta \boldsymbol{P}_{e} \partial t
$$

The $\triangle P \omega$ stabilizer makes use of the above relationship to simulate a signal proportional to the integral of mechanical power change by adding signals proportional to shaft-speed change and integral of electrical power change. On horizontal shaft units, this signal will contain torsional oscillations unless a filter is used (Anil, Ramesh, 2016). Because mechanical power changes are relatively slow, the derived integral of mechanical power signal can be conditioned with a low-pass filter to attenuate torsional frequencies. The overall transfer function for deriving the integral-of accelerating power signal from shaft speed and electrical power measurements is given by:

$$
\int \frac{\Delta P_{\mathrm{II}}}{2 H} \partial t \rightarrow \frac{\Delta P_{\varepsilon}}{2 H_{s}}+G(s)\left[\frac{\Delta P_{e}(s)}{2 H_{s}}+\Delta \omega(s)\right]
$$

Where, $G(s)$ is the transfer function of the low-pass filter.

The major advantage of a $\triangle P \omega$ stabilizer is that there is no need for a torsional filter in the main stabilizing path involving the $\Delta \boldsymbol{P}_{\boldsymbol{e}}$ signal. This alleviates the exciter mode stability problem, thereby permitting a higher stabilizer gain that result in better damping of system oscillations. A conventional end-of-shaft speed measurement or compensated frequency signal can be used with this structure.

\subsection{GENERIC POWER SYSTEM STABILIZER (PSS)}

The Generic Power System Stabilizer (PSS) block can be used to add damping to the rotor oscillations of the synchronous machine by controlling its excitation. The disturbances occurring in a power system induce electromechanical oscillations of the electrical generators. These oscillations, also called power swings, must be effectively damped to maintain the system stability. The output signal of the PSS is used as an additional input (Vstab) to the Excitation System block. The PSS input signal can be either the machine speed deviation, $d w$, or its acceleration power, $\mathrm{Pa}=\mathrm{Pm}$ - Pe (difference between the mechanical power and the electrical power). The Generic Power System Stabilizer is modeled by the following nonlinear system shown in Figure 2.3: 


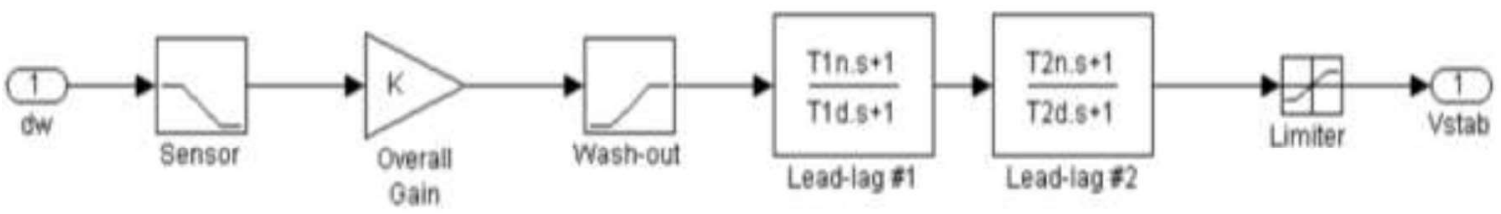

Figure 2.3: $\quad$ The Generic Power System Stabilizer

To ensure a robust damping, the PSS should provide a moderate phase advance at frequencies of interest in order to compensate for the inherent lag between the field excitation and the electrical torque induced by the PSS action.

The model consists of a low-pass filter, a general gain, a washout high-pass filter, a phase compensation system, and an output limiter. The general gain $\mathrm{K}$ determines the amount of damping produced by the stabilizer. The washout high-pass filter eliminates low frequencies that are present in the $d w$ signal and allows the PSS to respond only to speed changes. The phase-compensation system is represented by a cascade of two first-order lead-lag transfer functions used to compensate the phase lag between the excitation voltage and the electrical torque of the synchronous machine.

\subsection{MULTIBAND POWER SYSTEM STABILIZER}

The disturbances occurring in a power system induce electromechanical oscillations of the electrical generators. These oscillations, also called power swings, must be effectively damped to maintain the system's stability. Electromechanical oscillations can be classified in four main categories:

1) Local oscillations: between a unit and the rest of the generating station and between the latter and the rest of the power system. Their frequencies typically range from 0.8 to $4.0 \mathrm{~Hz}$.

2) Interplant oscillations: between two electrically close generation plants. Frequencies can vary from 1 to $2 \mathrm{~Hz}$.

3) Inter-area oscillations: between two major groups of generation plants. Frequencies are typically in a range of 0.2 to $0.8 \mathrm{~Hz}$.

4) Global oscillation: characterized by a common in-phase oscillation of all generators as found on an isolated system. The frequency of such a global mode is typically under $0.2 \mathrm{~Hz}$.

The need for effective damping of such a wide range, almost two decades, of electromechanical oscillations motivated the concept of the multiband power system stabilizer (MB-PSS). As its name reveals, the MB-PSS structure is based on multiple working bands. Three separate bands are used, respectively dedicated to the low-, intermediate-, and high-frequency modes of oscillations: the low band is typically associated with the power system global mode, the intermediate with the inter-area modes, and the high with the local modes.

Each of the three bands is made of a differential bandpass filter, a gain, and a limiter (see the Figure 3 which is Conceptual Representation). The outputs of the three bands are summed and passed through a final limiter producing the stabilizer output Vstab. This signal then modulates the set point of the generator voltage regulator so as to improve the damping of the electromechanical oscillations. To ensure robust damping, the MB-PSS should include a moderate phase advance at all frequencies of interest to compensate for the inherent lag between the field excitation and the electrical torque induced by the MB-PSS action (Shahgholian, Etesami, 2011). 


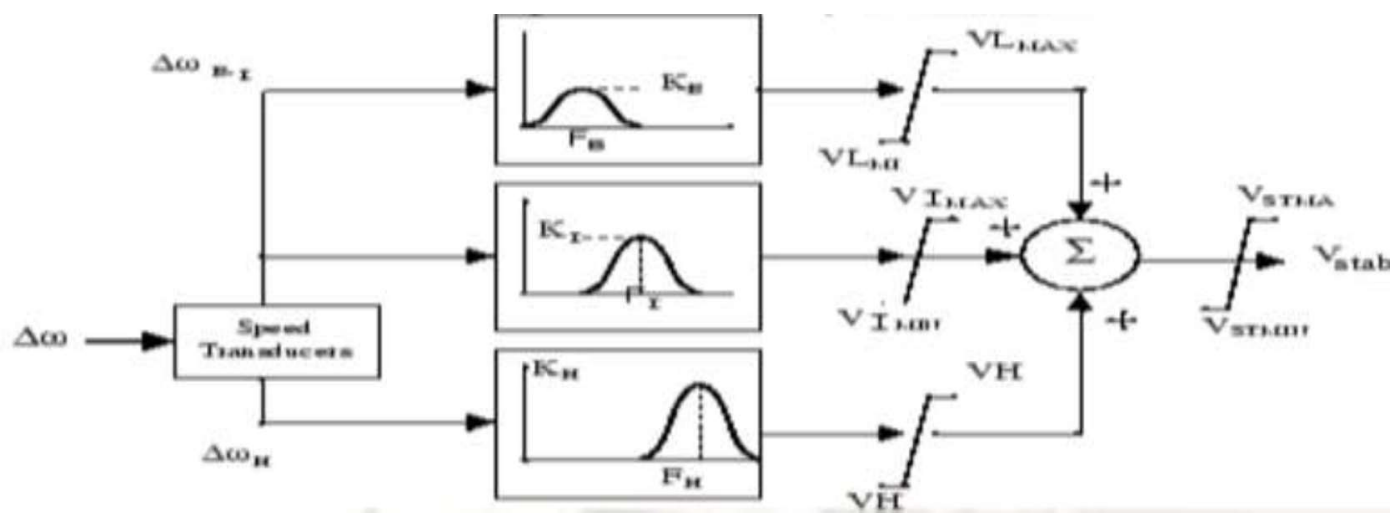

Figure 2.4: $\quad$ Conceptual Representation (Mahmud, Hossain, Pota, 2013)

\section{METHODOLOGY}

3.1 Stability of an Electric Power System Employing PSS

Matlab Simulink environment was used in analyzing a simple transmission system containing two hydraulic power plants. Power system stabilizers (PSSs) were used to improve transient stability and power oscillation damping of the system. The phasor simulation method was employed to demonstrate the effectiveness of the controller.

\subsection{DESCRIPTION OF THE TWO MACHINE ELECTRIC POWER SYSTEM}

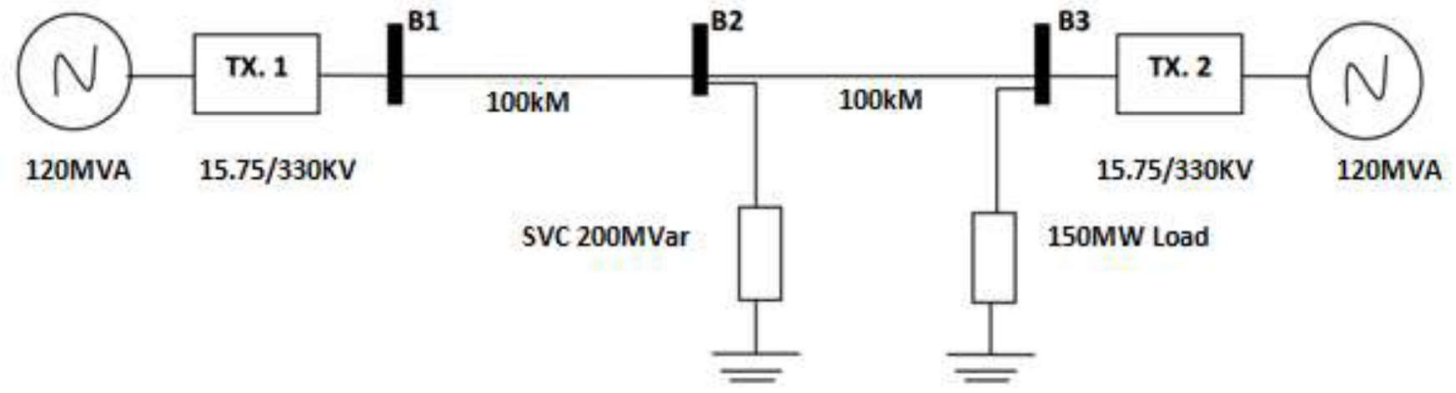

Fig. 3.1: Line Diagram of the Power System under Study

The modeling of a simple $330 \mathrm{KV}$ transmission system containing two hydraulic power plants is shown in Fig. 1. PSSs are used to improve transient stability and power system oscillations damping. Despite the simple structure of the illustrated power system in the figure, the phasor simulation method can be used to simulate more complex power grids. A $120 \mathrm{MW}$ hydraulic generation plant (machine M1) connected to a load centre through a $330 \mathrm{kV}, 200 \mathrm{~km}$ transmission line. The load centre was modelled by a $150 \mathrm{MW}$ resistive load. The load was fed by the remote $150 \mathrm{MW}$ plant and a local generation of $120 \mathrm{MW}$ (machine M2). The two machines were equipped with a Hydraulic Turbine and Governor (HTG), Excitation system and Power System Stabilizer (PSS). These blocks are located in the two 'Turbine and Regulator' subsystems of the simulation block diagram. Two types of stabilizers can be selected:

a) A generic model using the acceleration power $\left(\mathrm{p}_{\mathrm{a}}=\right.$ difference between mechanical power $\mathrm{p}_{\mathrm{m}}$ and output electrical power $\mathrm{p}_{\mathrm{eo}}$ ) and

b) A Multi-band stabilizer using the speed deviation (dw). 
The stabilizer type can be selected by specifying a value $\left(0=\right.$ No PSS, $1=p_{a}$ PSS or $2=d w$ MB PSS $)$ in the PSS constant block.

Figure 3.1 shows the use of the phasor solution for transient stability analysis of multi-machine systems which is a Simulink model of Figure 4.1. It analyzes the enhancement of transient stability of a two-machine transmission system with Power System Stabilizers (PSS).

Different faults especially a single phase faults were applied on the $330 \mathrm{kV}$ transmission system and the impact of PSS

\section{RESULTS AND DISCUSSION}

4mpact of PSS on Two Machine System with Single-Phase Fault

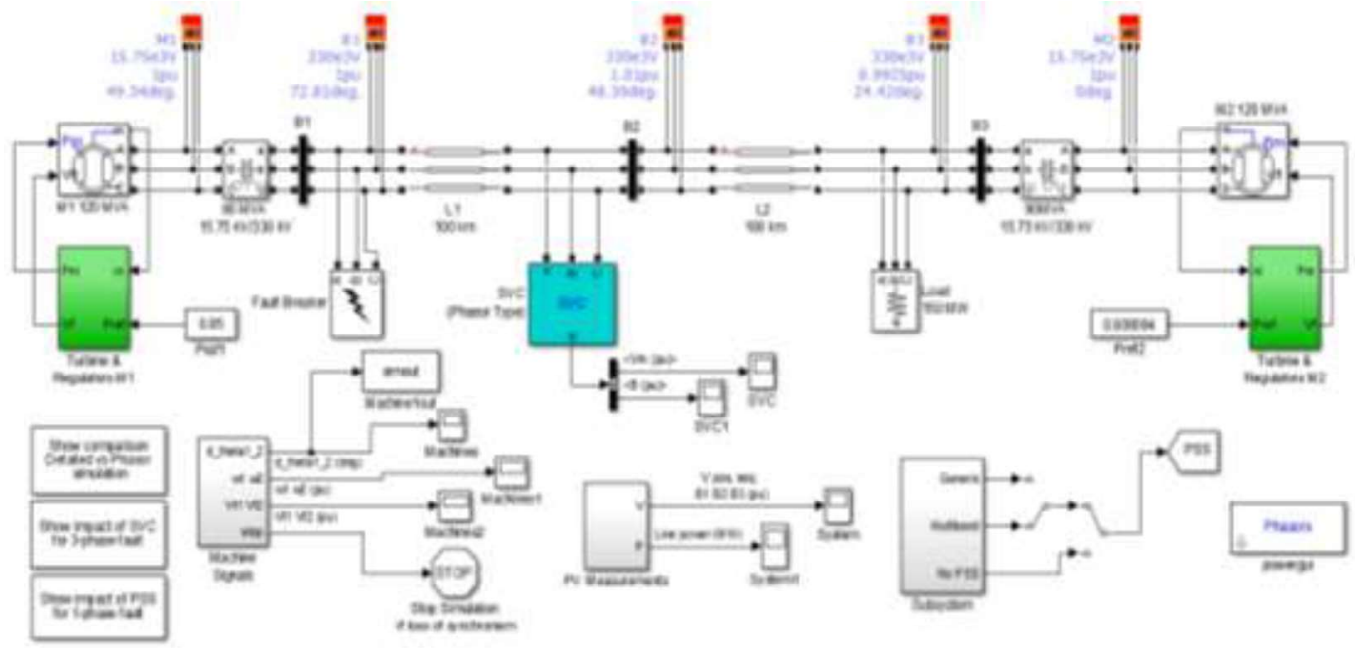

Figure 4.1: $\quad$ Simulation Model of the system

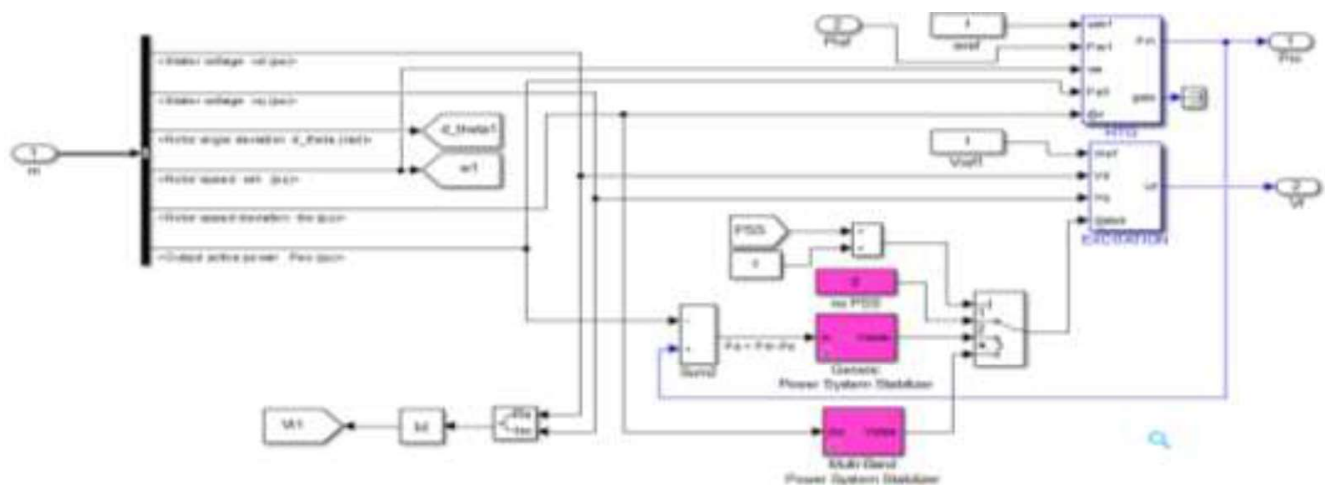

Figure 4.2: $\quad$ Turbine and Regulator M1

A single-phase fault was applied to the system in the transition time of $5.0 \mathrm{~s}$ to $5.2 \mathrm{~s}$. Without the application of PSSs, the generated data are clearly shown in table 4.1, table 4.2 shows when Multiband PSS is in operation and table 4.3 indicated Generic PSS values in operation for angles d theta1_2 (deg), speed $\mathrm{w}_{1}$ and $\mathrm{w}_{2}$ with voltage $\mathrm{Vm}$ in per unit value. The oscillation of the system was as indicated in Fig. 4 


\begin{tabular}{|c|c|c|c|c|c|c|}
\hline s/no & Time & $\begin{array}{l}\text { no } \\
\text { pss }\end{array}$ & $\begin{array}{l}\text { d_theta1_2 } \\
\text { (deg) }\end{array}$ & w1(pu) & $\mathrm{w} 2(\mathrm{pu})$ & $<\mathrm{Vm}(\mathrm{pu})>$ \\
\hline 1 & 0 & 0 & 53.0626 & 1 & 1 & 1 \\
\hline 2 & 0.0004 & 0 & 53.06258 & 0.999963 & 0.999971 & 0.964279 \\
\hline 3 & 0.00098 & 0 & 53.06231 & 0.999775 & 0.999821 & 0.925166 \\
\hline 4 & 0.00157 & 0 & 53.06148 & 0.999434 & 0.999548 & 0.896731 \\
\hline 5 & 0.00208 & 0 & 53.06012 & 0.999032 & 0.999221 & 0.87762 \\
\hline 6 & 0.00208 & 0 & 53.06012 & 0.999032 & 0.999221 & 0.87762 \\
\hline 7 & 0.00209 & 0 & 53.06007 & 0.999019 & 0.999211 & 0.877131 \\
\hline 8 & 0.00209 & 0 & 53.06007 & 0.999019 & 0.999211 & 0.877131 \\
\hline 9 & 0.00267 & 0 & 53.05752 & 0.998443 & 0.998737 & 0.858187 \\
\hline 10 & 0.00326 & 0 & 53.05386 & 0.997787 & 0.99819 & 0.840425 \\
\hline 11 & 0.00676 & 0 & 53.01307 & 0.994457 & 0.995227 & 0.696752 \\
\hline 12 & 0.00734 & 0 & 53.00505 & 0.994296 & 0.995053 & 0.664105 \\
\hline 13 & 0.00792 & 0 & 52.99725 & 0.994279 & 0.995007 & 0.62953 \\
\hline 14 & 0.00851 & 0 & 52.98979 & 0.994392 & 0.995083 & 0.593461 \\
\hline 15 & 0.00909 & 0 & 52.98274 & 0.994615 & 0.995267 & 0.556357 \\
\hline
\end{tabular}

\begin{tabular}{|c|c|c|c|c|c|c|}
\hline s/no & Time & multiband & $\begin{array}{l}\text { d_theta1_2 } \\
\text { (deg) }\end{array}$ & $\mathrm{w} 1(\mathrm{pu})$ & $\mathrm{w} 2(\mathrm{pu})$ & $<\mathrm{Vm}(\mathrm{pu})>$ \\
\hline 1 & 0 & 2 & 53.0626 & 1 & 1 & 1 \\
\hline 2 & 0.0004 & 2 & 53.0626 & 0.99996 & 0.99997 & 0.964279 \\
\hline 3 & 0.00098 & 2 & 53.0623 & 0.99978 & 0.99982 & 0.925166 \\
\hline 4 & 0.00157 & 2 & 53.0615 & 0.99943 & 0.99955 & 0.896731 \\
\hline 5 & 0.00208 & 2 & 53.0601 & 0.99902 & 0.99922 & 0.877345 \\
\hline 6 & 0.00208 & 2 & 53.0601 & 0.99902 & 0.99922 & 0.877345 \\
\hline 7 & 0.00209 & 2 & 53.06 & 0.99901 & 0.99921 & 0.876906 \\
\hline 8 & 0.00209 & 2 & 53.06 & 0.99901 & 0.99921 & 0.876906 \\
\hline 9 & 0.00267 & 2 & 53.0575 & 0.99844 & 0.99873 & 0.857988 \\
\hline 10 & 0.00326 & 2 & 53.0538 & 0.99778 & 0.99818 & 0.840228 \\
\hline 11 & 0.00676 & 2 & 53.013 & 0.99445 & 0.99522 & 0.696404 \\
\hline 12 & 0.00734 & 2 & 53.005 & 0.9943 & 0.99505 & 0.663734 \\
\hline 13 & 0.00792 & 2 & 52.9972 & 0.99428 & 0.99501 & 0.62914 \\
\hline 14 & 0.00851 & 2 & 52.9897 & 0.99439 & 0.99508 & 0.593057 \\
\hline 15 & 0.00909 & 2 & 52.9827 & 0.99462 & 0.99527 & 0.555944 \\
\hline
\end{tabular}




\begin{tabular}{|c|c|c|c|c|c|c|}
\hline $\mathrm{s} / \mathrm{no}$ & Time & generic & $\begin{array}{l}\text { d_theta1_2 } \\
(\overline{d e g})\end{array}$ & w1(pu) & $\mathrm{w} 2(\mathrm{pu})$ & $<\mathrm{Vm}(\mathrm{pu})>$ \\
\hline 1 & 0 & 1 & 53.0626 & 1 & 1 & 1 \\
\hline 2 & 0.0004 & 1 & 53.06258 & 0.999963 & 0.999971 & 0.964279 \\
\hline 3 & 0.00098 & 1 & 53.06231 & 0.9997752 & 0.999821 & 0.925166 \\
\hline 4 & 0.00157 & 1 & 53.06148 & 0.9994341 & 0.999548 & 0.896731 \\
\hline 5 & 0.00208 & 1 & 53.0613 & 0.9993732 & 0.999498 & 0.877345 \\
\hline 6 & 0.00208 & 1 & 53.0613 & 0.9993732 & 0.999498 & 0.877345 \\
\hline 7 & 0.00209 & 1 & 53.06116 & 0.9993276 & 0.999462 & 0.876906 \\
\hline 8 & 0.00209 & 1 & 53.06116 & 0.9993276 & 0.999462 & 0.876906 \\
\hline 9 & 0.00267 & 1 & 53.05927 & 0.9988199 & 0.999048 & 0.857988 \\
\hline 10 & 0.00326 & 1 & 53.05632 & 0.9982102 & 0.998544 & 0.840228 \\
\hline 11 & 0.00676 & 1 & 53.0182 & 0.9946335 & 0.995402 & 0.696404 \\
\hline 12 & 0.00734 & 1 & 53.01012 & 0.9943806 & 0.995148 & 0.663734 \\
\hline 13 & 0.00792 & 1 & 53.00216 & 0.9942734 & 0.995021 & 0.62914 \\
\hline 14 & 0.00851 & 1 & 52.99447 & 0.9943057 & 0.995021 & 0.593057 \\
\hline 15 & 0.00909 & 1 & 52.98716 & 0.9944615 & 0.995139 & 0.555944 \\
\hline
\end{tabular}

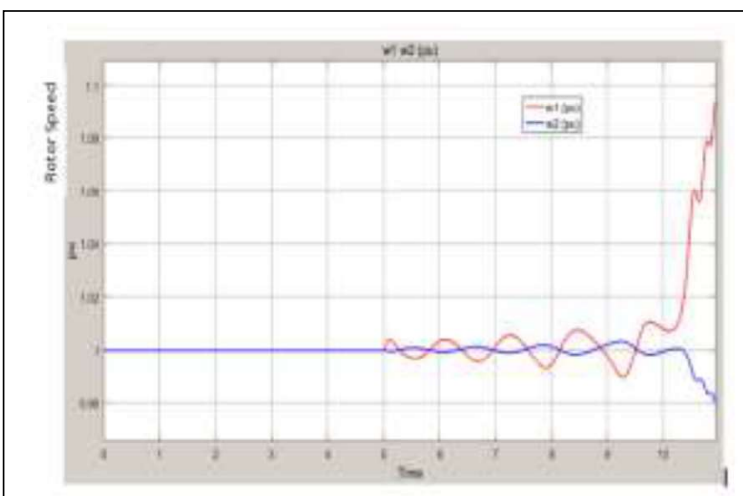

Figure 4.3: Rotor Speed of the two machines M1 and M2 ( $\mathrm{w}_{1}$ and $\mathrm{w}_{2}$ respectively) without PSSs

The response of the angular speed of machine M1 and M2 during the occurrence of a single line-to-ground phase fault. There are two lines on the graph: the red line represents machine M1 while the blue line represents machine M2. The oscillations in the machine speeds were evidently shown to have refused to die out after the fault was cleared at 5.1s; therefore the system remained unstable

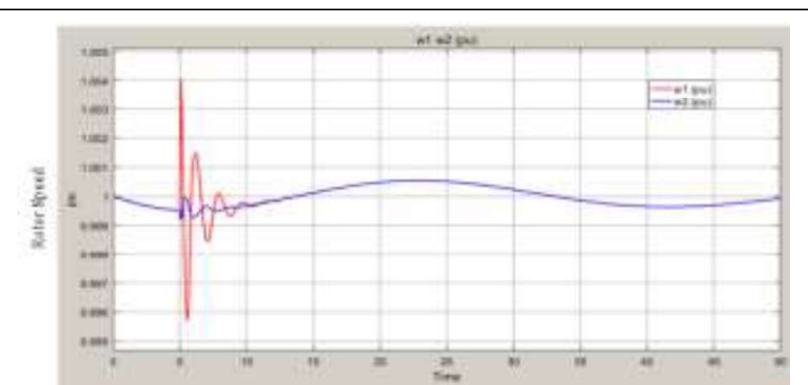

Figure 4.6: Rotor Speed of the two machines M1 and M2 with PSS

The machine 1 speed increased during the fault because during that period its electrical power was lower than its mechanical power. By simulating over a long period of time (50 seconds) it was noticed that the machine speeds oscillate together at a low frequency $(0.025 \mathrm{~Hz})$ after fault clearing, Fig.4.2 The two PSS (Pa type) succeed to damp the $0.8 \mathrm{~Hz}$ mode but they are not efficient for damping the $0.025 \mathrm{~Hz}$ mode. Selecting the Multi-band PSS resulted in both the $0.8 \mathrm{~Hz}$ and 0.025 mode oscillations being damped. 


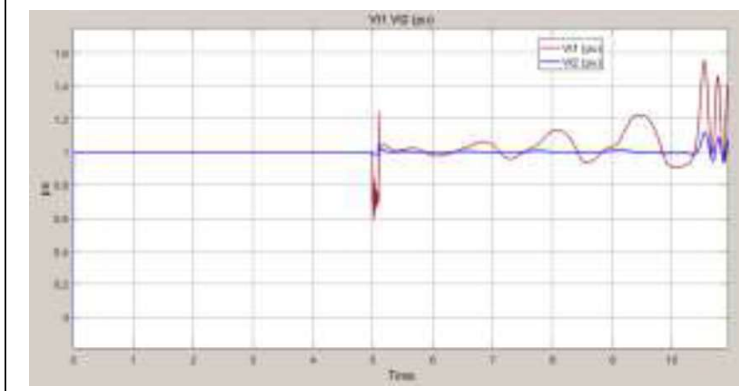

Figure 4.4: Terminal Voltages of the two machines M1 and M2 without PSSs

The response of the terminal voltages of machine M1 and M2 during the occurrence of a single line-to-ground phase fault. There are two lines on the graph: the red line represents machine M1 while the blue line represents machine M2. The oscillations in the terminal voltages were evidently shown to have refused to die out after the fault was cleared at $5.1 \mathrm{~s}$, therefore the system has remained unstable.

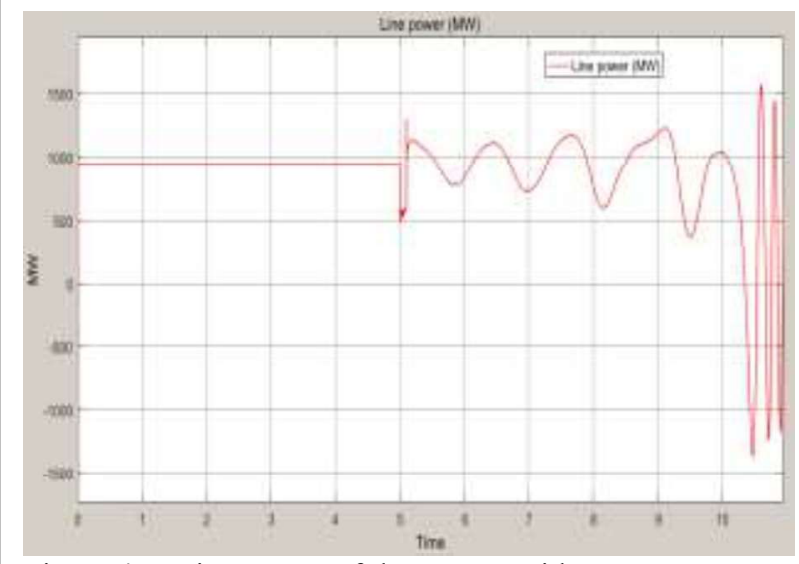

Figure 4.5: Line Power of the system without PSSs.

It can be seen that the line power transfer was lost after the $0.8 \mathrm{~Hz}$ oscillation was damped after fault clearance at 5.1s.

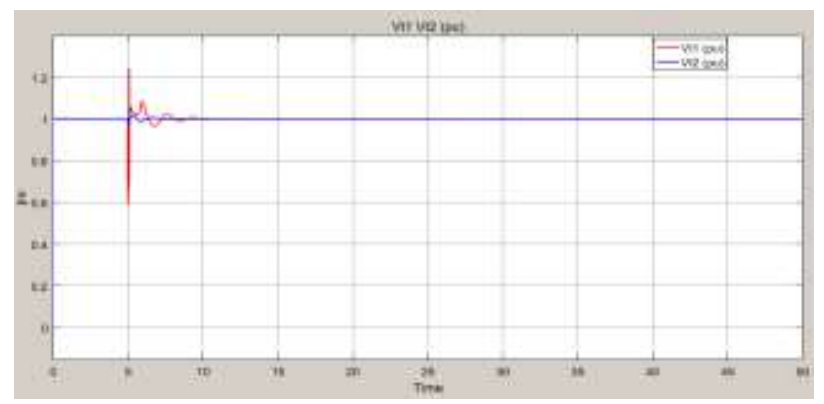

Figure 4.7: Terminal Voltages of the two machines M1 and M2 with PSS

During the occurrence of a single line-to-ground phase fault, there are two lines on the graph: the red line represents machine M1 while the blue line represents machine M2. The terminal voltages were evidently shown to have regained stability after the fault was cleared at $5.1 \mathrm{~s}$.

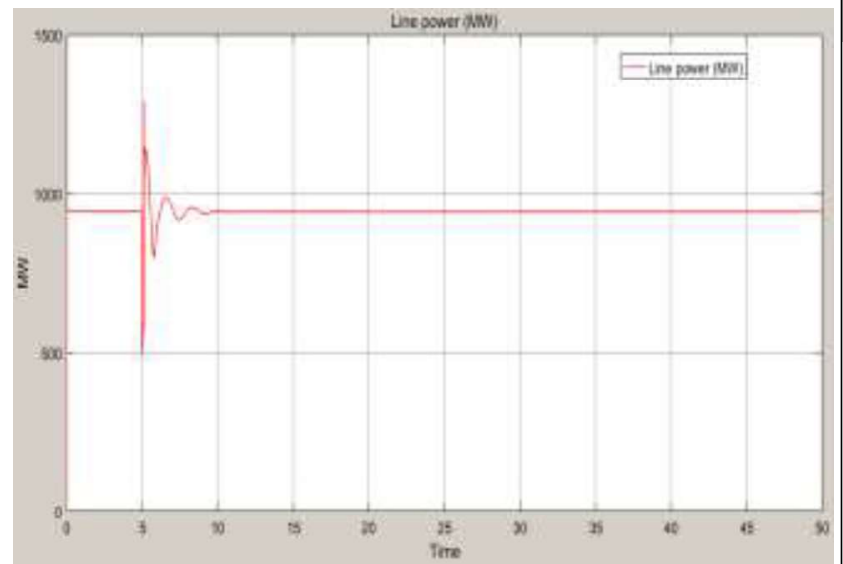

Figure 4.8: Line Power of the system with PSSs

This shows the effect of single line-to-ground fault on the system line power. It can be seen that the line power transfer was not lost after the oscillation was damped after fault clearance. 

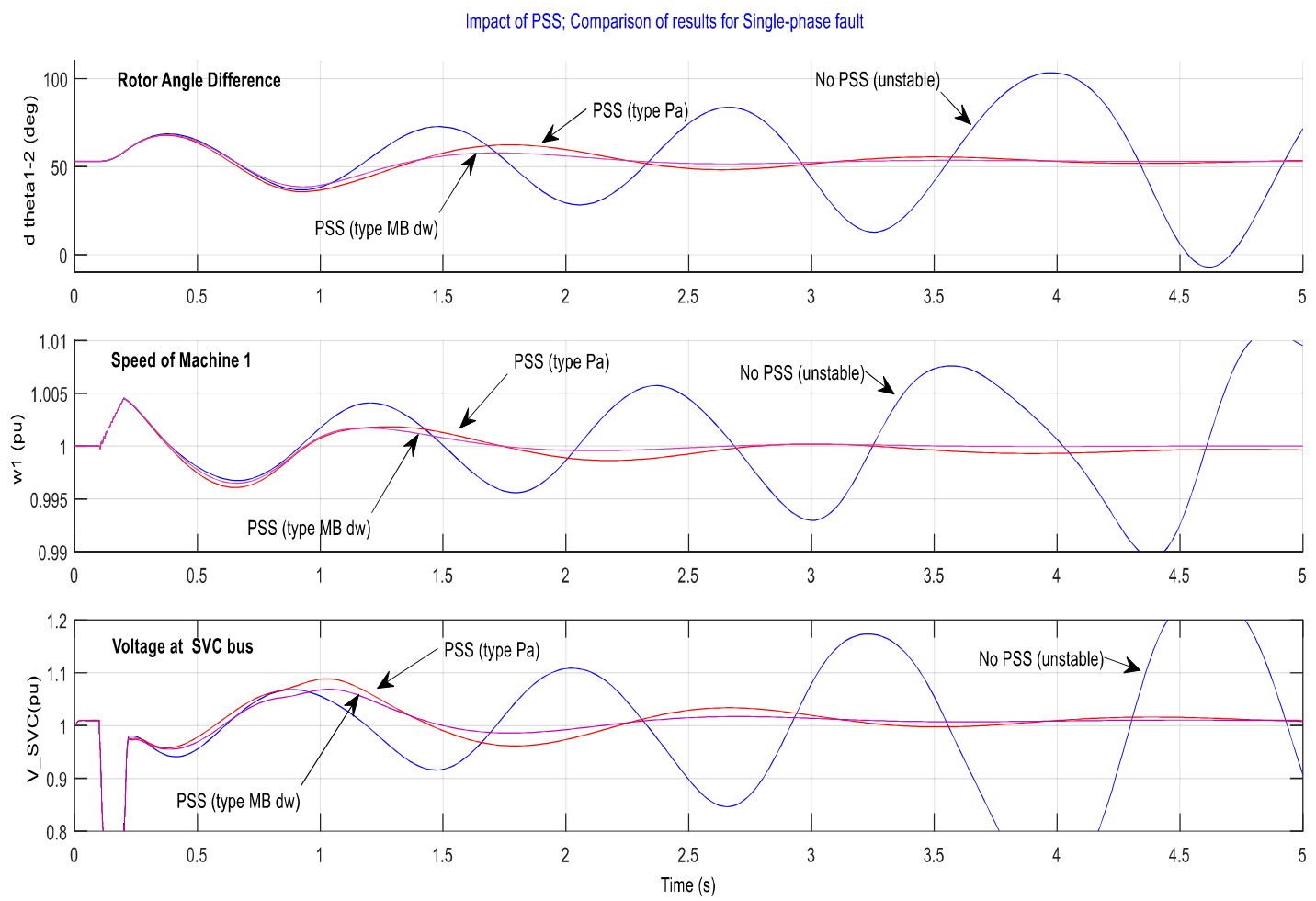

Figure 4.9: Impact of PSS; Comparison of results for Single-phase fault

Figure 4.9 shows the comparison of the simulation results obtained when the two types of PSS (Generic and Multiband PSS) were put into services. It can be seen from the Figure that performance of the Multiband PSS was better than that of Generic PSS as it offered less oscillation. As indicated by the blue curve the system became unstable without either PSSs.

\section{CONCLUSION}

A study of the impacts of Power System Stabilizer (PSS) has been carried out. The function of these controllers was discussed in brief and their effectiveness in enhancing power system stability assessed. From the results obtained and by comparing the two types of PSS, the performance of the Multiband PSS were better than that of Generic PSS as it offered less oscillation. To guarantee the robustness of the proposed controller, the design process was carried out considering a wide range of operating conditions: Heavy, normal and light loading. It has wide application in the operation and control of power systems, such as scheduling power flow; decreasing unsymmetrical components; reducing net loss; providing voltage support; limiting short-circuit currents; damping power oscillations; and enhancing transient stability.

\section{REFERENCES}

Abd-Elazim S.M., Ali E.S. (2012). Coordinated design of PSSs and SVC via bacteria foraging optimization algorithm in a multi-machine power system. Electrical Power and Energy System, 41 (1), 44-53.

Ali A. (2013). Development of system with transitory steadiness of a bi-machine transmission system with power system stabilizers and static Var compensator. International Journal of Engineering Research and Applications, 3(3), 1121-1125. 
Alok K., Surya Bhushan D. (2013). Enhancement of transient stability in transmission line using SVC facts controller" International Journal of Recent Technology and Engineering, 2(2).

Cardenas, R.; Pena, R.; Alepuz, S.; Asher, G. (2013). Overview of Control Systems for the Operation of DFIGs in Wind Energy Applications. IEEE Trans. Ind. Electr., 60, 2776-2798.

Hossain Sadi M. A., Hasan Ali M. (2014). Combined operation of SVC and optimal reclosing of circuit breakers for power system transient stability enhancement. Electric Power Systems Research, 106, 241-248.

Hussein, T. R. (2014). Using Power System Stabilizers (PSS) And Shunt Static Var Compensator (SVC) For Damping Oscillations in Electrical Power System. Journal of faculty MAAMOUN.

Khaleghi M., Hossein Nezamabadi-pour M. M., Lee K. Y. (2010). Pareto-optimical design of damping controllers using modified artificial immune algorithm. IEEE Trans. Power Syst., 41(2), 240-250.

Khalid K., Saleh H., Ercelebi E. (2015). Transient stability improvement in multimachine system using power system stabilizer (PSS) and static Var compensator (SVC). International Journal of Electrical, Computer, Energetic, Electronic and Communication Engineering, 09(12), 1362-1375.

Köse A., Irmak E. (2016). Modeling and Simulation of a Static VAR Compensator Based on FC-TCR" in 5th international conference on Renewable Energy Research and Applications, Birmingham UK.

Kunju Muhammed, L.P.; Pal, B.C.; Oates, C.; Dyke, K.J. (2016). Electrical oscillations in wind farm systems: Analysis and insight based on detailed modeling. IEEE Trans. Sustain. Energy, 7, 51-62.

Omar B. M., Samir H., Ahmed Z. S. (2016). Impact of PSS and SVC on The Power System Transient Stability. In 8th International Conference on Modelling, Identification and Control, Medea and Algiers Algeria.

Panda S., Padhy N. P., (2007). Power system with PSS and FACTS controller modeling, simulation and simultaneous employing genetic algorithm. International Journal of Electrical and Electronics Engineering, 9-18.

Shahgholian G., Etesami A. (2011). The effect of thyristor controlled series compensator on power system oscillation damping control. Int. Review of Elec. Eng., Vol. 5, No. 2, pp. 1822-1830.

Shahgholian G., Faiz J. (2010). Static synchronous compensator for improving performance of power system: A review. Int. Review of Elec. Eng., Vol. 4, No. 2, pp. 2333-2342.

Shahgholian G., Haghjoo E., Seifi A., Hassanzadeh I. (2011). The improvement DSTATCOM to enhance the quality of power using fuzzy-neural controller. J. of Intelligent Procedures in Electrical Technology, Vol. 2, No. 6, pp. 3-16.

Shahgholian G., Shafaghi P., Moalem S., Mahdavian M. (2009). Analysis and design of a linear quadratic regulator control for static synchronous compensator. IEEE/ICCEE, pp.65-69, Dubai. 